\title{
Profundidade e espaçamento da mandioca no plantio direto na palha
}

\author{
Depth and spacing of the cassava in no-tillage system
}

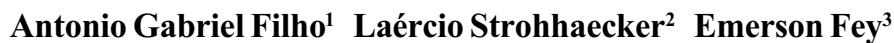

\section{RESUMO}

Conduziu-se um experimento em LATOSSOLO VERMELHO Eutroférrico de textura argilosa, localizado no municipio de Marechal Cândido Rondon - PR, onde se utilizou delineamento em blocos casualizados com arranjo fatorial $2 x$ 3 , 4 repetições e com dois espaçamentos: fileiras simples $(1,00$ $x 0,60 \mathrm{~m})$ e fileiras duplas $(1,50 \times 0,50 \times 0,60 \mathrm{~m})$, e três profundidades de plantio $(0,05,0,10$ e $0,15 \mathrm{~m})$. Nos dois tipos de espaçamentos, a população de plantas foi de 16.666 plantas ha ${ }^{-1}$. O plantio direto na palha de aveia foi feito com a abertura de covas. Estudou-se o diâmetro médio dos caules, índice de tombamento, esforço para o arranquio manual, teor de amido nas raizes, produtividade de raizes e de amido, determinados aos 17 meses após o plantio. A disposição das linhas em fileiras duplas e simples não afetou as variáveis estudadas. O plantio das manivas em profundidade de $0,15 \mathrm{~m}$ reduziu significativamente o indice de tombamento. Por outro lado, o plantio nessa profundidade dificultou a colheita, devido à maior resistência ao arranquio manual, além de reduzir significativamente a produtividade de raizes e amido. O plantio com $0,10 m$ de profundidade proporcionou a melhor produtividade de raizes e amido.

Palavras-chave: Manihot esculenta, distribuição de plantas, práticas de manejo.

\section{ABSTRACT}

The experiment was conducted in eutrophic Oxisol soil in Marechal Cândido Rondon, PR, Brazil. It consisted of planting cassava in a factorial design. Factors included two row design: simple $(1.00 \times 0.60 \mathrm{~m})$, double rank $(1.50 \times 0.50 \times$ $0.60 \mathrm{~m})$; and three planting depths $(0.05,0.10$ and $0.15 \mathrm{~m})$. Planting was accomplished in no-tillage system over oat straw.
Measured variables 17 months after planting included: stalk mean diameter; damping-off index; resistence to manual harvesting; root starch concentration; and productivity of root and starch. The results indicated that damping-off index was lower at $0.15 \mathrm{~m}$ planting depth. However, cassava planted at the $0.15 \mathrm{~m}$ depth demanded the higest labor for harvesting and the lowest root and starch productivities. The best root and starch productivity was achiered at the $0.10 \mathrm{~m}$ soil depth.

Key words: Cassava, no-tillage, row, planting depth.

\section{INTRODUÇ̃̃O}

As condições para desenvolvimento das plantas de mandioca no sistema de plantio direto na palha são muito diferentes, quando comparadas com o plantio convencional. O não revolvimento do solo permite maior espaço de tempo útil para o plantio, que deve ser realizado quando o solo apresenta teor de água suficiente para a brotação das manivas. A cobertura morta, principalmente de Avena strigosa, exerce efeitos alelopáticos sobre várias espécies de plantas daninhas (ALMEIDA, 1991), reduzindo sua competição com a cultura. Uma forte competição com plantas daninhas reduz significativamente a produtividade (STROHHAECKER et al., 2000).

A utilização do sistema de fileiras duplas na cultura da mandioca é recomendada, porque facilita os tratos culturais, aumenta a eficiência produtiva da área

\footnotetext{
${ }^{1}$ Engenheiro Agrônomo, Doutor, Professor Adjunto do Curso de Engenharia Agrícola, Universidade Estadual do Oeste do Paraná (UNIOESTE), Rua Universitária, 2069, 85814-110, Cascavel, PR. Email: gabriel@unioeste.br.Autor. Autor para correspondência.

${ }^{2}$ Engenheiro Agrônomo, ex-bolsista de iniciação científica PIBIC-CNPq-UNIOESTE.

${ }^{3}$ Engenheiro Agrônomo, MSc, Professor Assistente do Centro de Ciências Agrárias UNIOESTE, 85960-000, Mal. Cândido Rondon PR.
} 
cultivada, permite a consorciação com outras culturas nos espaçamentos maiores e a rotação de culturas na mesma área MATTOS et al. (1990).

Para a obtenção de rendimentos satisfatórios, também deve ser observado o fator profundidade de plantio das manivas. No plantio convencional, normalmente planta-se à profundidade de $0,10 \mathrm{~m}$. No entanto, sabe-se que o plantio em profundidades menores tende a produtividades maiores,mesmo que isso requeira muito cuidado para que as manivas não desidratem.

DERPSCH (1985), MONEGAT (1991) e CALEGARI (1993) enfatizam a importância da rotação com o uso de plantas de cobertura do solo no cultivo das culturas. Além de cobrirem o solo, diminuindo a ação erosiva da chuva, melhoram sua fertilidade natural, reduzem o ataque de pragas e doenças, que são mais intensos quando o cultivo de uma única espécie é realizado sucessivamente na mesma área.

GABRIEL FILHO et al. (2000), estudando o comportamento da mandioca em cultivo mínimo após a adubação verde com ervilhaca e aveia, verificaram que a produtividade de raízes e o esforço para o arranquio manual não foram afetados quando não se revolveu o solo. Os mesmos autores verificaram um adensamento sub-superficial do solo aos 90 dias após o plantio. A razão foi a falta de proteção contra o impacto das chuvas torrenciais na fase inicial da cultura da mandioca, permitindo ao solo acomodar-se rapidamente.

BRIEGUER \& GRANER (1941), NORMANHA \& PEREIRA (1950), MATTOS et al. (1982), MATTOS et al. (1984), MATTOS et al. (1990) e MATTOS et al. (1994) estudaram o plantio de mandioca em diferentes profundidades e espaçamentos, porém, as informações disponíveis tratam da cultura no sistema de preparo convencional do solo.

A adaptação do espaçamento para a mandioca em fileiras duplas, além das vantagens de utilização do consórcio com feijão (MATTOS et al., 1990) e amendoim (MATTOS et al., 1994), do cultivo mecânico, da redução da mão-de-obra, inspeção e aplicação de defensivos, aumenta os rendimentos em relação ao plantio tradicional (MATTOS et al., 1983; MATTOS et al., 1984; BESSA et al., 1986). Apesar de não terem obtido melhores rendimentos de raízes, QUEIROZ et al. (1988) recomendaram o plantio em fileiras duplas consorciadas com outras culturas, como o caupi (Vigna unguiculata (L) Walp), por facilitar o manejo da cultura consorciada. Por outro lado, BUENO (1986), estudando dez cultivares, sendo cinco de ramificação baixa e cinco de ramificação alta, plantadas em fileiras simples e duplas, durante dois anos, concluiu que o sistema de fileiras simples foi mais eficiente do que o de fileiras duplas, pois fileiras simples proporcionam maior rendimento de raízes devido, principalmente, ao maior número de raízes por planta formadas nas fileiras simples.

NORMANHA \& PEREIRA (1950) utilizaram três profundidades $(0,05,0,10$ e $0,15 \mathrm{~m})$ e duas estações de plantio durante três anos e concluíram que, sob condições de tempo quente e seco, as manivas plantadas a $0,15 \mathrm{~m}$ de profundidade brotaram mais depressa do que aquelas plantadas mais rasas, por causa, talvez, do aumento do teor de água na profundidade de $0,15 \mathrm{~m}$. Os mesmos autores também afirmaram que o oposto era verdadeiro quando a temperatura e o teor de água eram adequados. A colheita é muito mais fácil para as manivas plantadas a $0,05 \mathrm{~m}$ de profundidade do que para aquelas plantadas a $0,15 \mathrm{~m}$, devido à profundidade das raízes dessas últimas.

CAMPOS \& SENA (1974), objetivando medir a profundidade das raízes da mandioca, plantaram manivas com $0,20 \mathrm{~m}$ de comprimento em sulcos com $0,10 \mathrm{~m}$ de profundidade, na posição horizontal e espaçada 1,00 x 0,60 metros de distância. Os resultados indicaram que as raízes alcançaram profundidade de 0,90 e $1,40 \mathrm{~m}$ no período de 140 e 365 dias, respectivamente. Dentro da profundidade de $0,30 \mathrm{~m}$ foram encontradas 95,3 e $96,4 \%$ de todas as raízes, e destas 65,6 e $85,7 \%$ desenvolvidas nos $0,10 \mathrm{~m}$ superficiais do solo.

CELIS \& TORO (1974) relataram que as manivas podem ser plantadas no raso ou profundamente, em qualquer uma das posições (vertical, inclinada a $45^{\circ}$ e horizontal).

TAN \& BERTRAND (1972) afirmaram que a profundidade de plantio deve ser regulada de acordo com as condições ambientais, pois uma exposição muito grande das manivas nas áreas onde o teor de água do solo esteja aquém das condições favoráveis pode resultar em desidratação das mesmas e, conseqüentemente, baixos rendimentos.Segundo BRIEGER \& GRANER (1941), o plantio à profundidade de $0,05 \mathrm{~m}$ fornece as melhores condições de aeração e formação das raízes. Entretanto, o plantio na horizontal é recomendado em profundidade um pouco maior, para melhorar as condições de umidade das manivas.

Quanto ao direcionamento do sistema radicular das plantas de mandioca, há uma tendência de elas dirigirem-se para os espaçamentos entre as fileiras duplas (MATTOS et al., 1982). O número de raízes por planta cresce quando o espaçamento entre fileiras e dentro delas é aumentado (MATTOS et al., 1984).

O presente trabalho visa estudar o comportamento da cultura da mandioca plantada no 
espaçamento tradicional e num espaçamento alternativo de fileiras duplas, mantendo a população de plantas igual em ambos, combinado com três profundidades de plantio das manivas.

\section{MATERIAL E MÉTODOS}

O experimento foi implantado na estação experimental Antônio Carlos dos Santos Pessoa, localizada na Linha Guará (Longitude: W $54^{\circ} 01^{\prime}$ 9,09' a W 54 01' 45,15'; Latitude: S 24 31' 42,17' a S 24 32' 15,34"; Altitude: $420 \mathrm{~m}$ ), pertencente à Unioeste, Campus de Marechal Cândido Rondon, em outubro de 1998, terminando em abril de 2000. Utilizou-se a cultivar "Fécula Vermelha de Uma Rama" em área com restevas de aveia branca (Avena sativa).

O clima da região é Subtropical úmido, com temperatura média anual de $18^{\circ} \mathrm{C}$ e precipitação pluviométrica média anual de $1804 \mathrm{~mm}$. O solo da área experimental foi classificado como LATOSSOLO VERMELHO Eutroférrico, de textura muito argilosa $(66,8$ $\%$ de argila, $27,9 \%$ de silte e $5,3 \%$ de areia, na profundidade de 0,00 a $0,20 \mathrm{~m})$. A análise química, na implantação do experimento, mostrou as seguintes características na profundidade de 0 a $20 \mathrm{~cm}: \mathrm{pH}$ em $\mathrm{CaCl}_{2}(0,01 \mathrm{M})=5,34$; saturação de bases $=54,6 \% ; \mathrm{P}=$ $8,5 \mathrm{mg} \mathrm{dm}^{-3}$ (extrator Mehlich-1); $\mathrm{K}=0,26 \mathrm{cmol}_{\mathrm{c}} \mathrm{dm}^{-3}$; $\mathrm{MO}=35,8 \mathrm{~g} \mathrm{~kg}^{-1} \mathrm{cmol}_{\mathrm{c}} \mathrm{dm}^{-3}, \mathrm{Ca}=4,84 \mathrm{cmol}_{\mathrm{c}} \mathrm{dm}^{-3}, \mathrm{Mg}=$ $2,37 \mathrm{cmol}_{\mathrm{c}} \mathrm{dm}^{-3}$ e $6,21 \mathrm{cmol}_{\mathrm{c}} \mathrm{dm}^{-3} \mathrm{de} \mathrm{H}+\mathrm{Al}$.

O sistema de plantio direto na palha completava o quarto ano de implantação na área com a cultura da aveia branca (Avena sativa), colhida para sementes antes do experimento.

Utilizou-se delineamento em blocos casualizados com arranjo fatorial $2 \times 3$, tendo dois espaçamentos: fileiras simples $(1,00 \times 0,60 \mathrm{~m})$ e fileiras duplas $(1,50 \times 0,50 \times 0,60 \mathrm{~m})$, e três profundidades de plantio $(0,05,0,10$ e $0,15 \mathrm{~m})$, com quatro repetições. As manivas com $0,20 \mathrm{~m}$ de comprimento foram colocadas horizontalmente nas covas

As parcelas de $6,00 \mathrm{~m}$ de comprimento e $3,50 \mathrm{~m}$ de largura apresentavam quatro fileiras, sendo que, nas avaliações, foram consideradas as duas fileiras centrais como parte útil, excluindo-se uma planta em cada extremidade. Assim, cada parcela apresentou 16 plantas úteis nas avaliações e a população foi de 16.666 plantas.ha ${ }^{-1}$.

Os tratos culturais basearam-se em capinas manuais com enxada aos 30, 60, 90, 300 e 420 dias após o plantio.

A contagem do número de plantas tombadas por parcela ocorreu 7 dias antes da colheita. O número encontrado foi inversamente relacionado com o total de plantas da parte útil de cada parcela, obtendo-se, então, o índice ou o percentual de tombamento.

A média do diâmetro dos caules foi realizada com um paquímetro digital a $0,40 \mathrm{~m}$ acima do solo, onde a maioria das plantas não apresentavam ramificações. As medidas foram tomadas nos internódios.

$\mathrm{O}$ esforço para o arranquio manual foi analisado de duas maneiras: a) através do esforço médio individual (esforço por planta); b) através da relação entre o esforço médio individual e a produtividade média de raízes por planta (esforço específico). Determinou-se o esforço para o arranquio manual com um dinamômetro de mola de capacidade máxima de $600 \mathrm{~N}$ (60 kgf), com um dispositivo para indicar a força máxima aplicada no equipamento para o arranquio das 12 plantas de mandioca. $\mathrm{O}$ somatório dos valores obtidos foi dividido pelo número de plantas amostradas. A unidade de medida de esforço por planta é quilogramaforça por planta $\left(\mathrm{kgf} \mathrm{planta}^{-1}\right)$. O esforço específico foi obtido indiretamente, através da relação inversa (divisão) entre a média do esforço por planta e a média da produtividade de raízes por planta de cada parcela $\left(\mathrm{kgf} \mathrm{kg}^{-1}\right)$

De cada parcela, foram retiradas três amostras de 3,0kg de raízes, nas quais se determinou a percentagem média de amido utilizando-se o método da balança hidrostática conforme GROSSMAN \& FREITAS (1950). Considerando-se a massa de raízes e a área útil de cada parcela, determinou-se a produtividade de raízes, expressa em quilograma por hectare $\left(\mathrm{kg} \mathrm{ha}^{-1}\right)$.

Obteve-se a produtividade de amido através da relação direta entre a produtividade de raízes e a percentagem média de amido de cada parcela, sendo os valores expressos em quilograma por hectare $\left(\mathrm{kg} \mathrm{ha}^{-1}\right)$.

As avaliações das variáveis estudadas foram realizadas aos 17 meses após o plantio. Os valores obtidos foram submetidos à análise de variância e as médias comparadas pelo teste de Tukey, considerando-se $5 \%$ de probabilidade para ambos os testes. Realizou-se, também, a análise de variância com desdobramento da soma do quadrado do fator profundidade em efeitos de regressão linear $\left(1^{\circ}\right.$ grau $) \mathrm{e}$ quadrático ( $\left.2^{\circ} \mathrm{grau}\right)$.

\section{RESULTADOS E DISCUSSÃO}

Os valores médios do índice de tombamento, diâmetro do caule, esforço de arranquio individual e esforço específico, percentagem de amido, produtividade de raízes e produtividade de amido em função dos espaçamentos de plantio estão apresentados na tabela 1 . 
Tabela 1 - Índice de tombamento, diâmetro do caule, esforço de arranquio individual e esforço específico, percentagem de amido, produtividade de raízes e produtividade de amido em função dos espaçamentos de plantio. Marechal Cândido Rondon/PR, 2000.

\begin{tabular}{|c|c|c|c|c|c|c|c|}
\hline \multicolumn{8}{|c|}{ Variáveis } \\
\hline & $\begin{array}{c}\text { Índice de } \\
\text { tombamento(\%) }\end{array}$ & $\begin{array}{l}\text { Diâmetro do } \\
\text { caule }(\mathrm{mm})\end{array}$ & $\begin{array}{l}\text { Esforço } \\
\text { individual } \\
\left(\mathrm{kgf} \mathrm{pl}^{-1}\right)\end{array}$ & $\begin{array}{l}\text { Esforço } \\
\text { específico } \\
\left(\mathrm{kgf} \mathrm{kg}^{-1}\right)\end{array}$ & $\begin{array}{c}\text { Teor de amido } \\
(\%)\end{array}$ & $\begin{array}{l}\text { Prod. de raízes } \\
\qquad\left(\mathrm{kg} \mathrm{ha}^{-1}\right)\end{array}$ & $\begin{array}{l}\text { Prod. de amido } \\
\quad\left(\mathrm{kg} \mathrm{ha}^{-1}\right)\end{array}$ \\
\hline \multicolumn{8}{|c|}{ Espaçamentos } \\
\hline simples & $15,63 \mathrm{a}$ & $35,45 \mathrm{a}$ & $52,28 \mathrm{a}$ & $21,24 \mathrm{a}$ & $20,2 \mathrm{a}$ & $41.309 \mathrm{a}$ & $8.369 \mathrm{a}$ \\
\hline duplo & $18,23 \mathrm{a}$ & $34,99 \mathrm{a}$ & $52,04 \mathrm{a}$ & $22,89 \mathrm{a}$ & $20,0 \mathrm{a}$ & $37.579 \mathrm{a}$ & $7.562 \mathrm{a}$ \\
\hline DMS & 6,21 & 1,58 & 2,66 & 2,82 & 1,6 & 4.406 & 1.105 \\
\hline \multicolumn{8}{|c|}{ Profundidades (m) } \\
\hline 0,05 & $21,09 \mathrm{a}$ & $35,55 \mathrm{a}$ & $47,58 \mathrm{~b}$ & $20,07 \mathrm{~b}$ & $20,2 \mathrm{a}$ & $39.166 \mathrm{~b}$ & $7.866 \mathrm{ab}$ \\
\hline 0,10 & $23,44 \mathrm{a}$ & $34,75 \mathrm{a}$ & $51,42 \mathrm{~b}$ & $17,91 \mathrm{~b}$ & $20,2 \mathrm{a}$ & $46.250 \mathrm{a}$ & $9.404 \mathrm{a}$ \\
\hline 0,15 & $6,25 \mathrm{~b}$ & $35,35 \mathrm{a}$ & $57,48 \mathrm{a}$ & $28,20 \mathrm{a}$ & $20,0 \mathrm{a}$ & $32.918 \mathrm{~b}$ & $6.626 \mathrm{~b}$ \\
\hline DMS & 9,25 & 2,35 & 3,97 & 4,21 & 2,4 & 6.580 & 1.650 \\
\hline $\mathrm{CV} \%$ & 42,2 & 5,2 & 5,9 & 14,7 & 9,2 & 12,9 & 16,0 \\
\hline
\end{tabular}

Médias seguidas pela mesma letra não diferem estatisticamente pelo teste de Tukey em 5\% de probabilidade.

Para o índice de tombamento, a profundidade de $0,15 \mathrm{~m}$ apresentou redução significativa em relação às demais profundidades. Os espaçamentos e a interação dos fatores não apresentaram variações significativas. A redução do índice de tombamento no plantio em $0,15 \mathrm{~m}$ de profundidade ocorreu, possivelmente, porque o solo acima das raízes exerceu maior resistência ao deslocamento vertical das mesmas. As plantações de mandioca estão sujeitas a muitas adversidades climáticas. As chances dessa cultura sofrer danos devido, principalmente, aos ventos é grande, aumentando ainda mais quando a cultura permaneceu por mais de um ciclo vegetativo na lavoura. No diâmetro médio dos caules, os tratamentos em separado e a interação não apresentaram variações estatisticamente significativas. O desenvolvimento individual das plantas de mandioca da cultivar utilizada foi semelhante tanto no plantio em fileiras duplas, quanto em fileiras simples. Em cultivares que apresentam ramificações secundárias e terciárias (diferentes da cultivar utilizado no experimento), podem ocorrer modificações nas características dendométricas, principalmente se utilizadas em espaçamento duplo.

Para o esforço médio de arranquio manual por planta, a utilização de espaçamentos simples ou duplos não demonstrou efeitos significativos no esforço médio individual. $\mathrm{O}$ plantio na profundidade de $0,15 \mathrm{~m}$ aumentou significativamente o esforço médio individual em relação às profundidades de $0,05 \mathrm{e} 0,10 \mathrm{~m}$. Estes resultados estão condizentes com NORMANHA \& PEREIRA (1950), os quais relataram que a colheita é muito mais fácil para as manivas plantadas a $0,05 \mathrm{~m}$ de profundidade do que para aquelas plantadas a $0,15 \mathrm{~m}$, devido à profundidade das raízes dessas últimas. Não houve interação entre os tratamentos estudados, ou seja, a combinação entre os espaçamentos e profundidades de plantio não alterou o esforço médio individual de arranquio. Os valores relativamente altos do esforço para o arranquio manual aconteceram, possivelmente, pela permanência por mais de um ciclo vegetativo da cultura antes da colheita, que aumentou a massa de raízes. GABRIEL FILHO et al. (2000) obtiveram valores médios menores, porém, a colheita foi realizada com apenas um ciclo vegetativo.

Os dois espaçamentos utilizados não manifestaram variação significativa no esforço específico. Um aumento significativo ocorreu quando as manivas foram plantadas a $0,15 \mathrm{~m}$ de profundidade. Isto significa dizer que, para o arranquio de $1.000 \mathrm{~kg}$ de raízes à profundidade de $0,15 \mathrm{~m}$, há um dispêndio de 28.200kgf. A análise estatística também não acusou interação entre os tratamentos estudados.

As percentagens de amido nas raízes não foram afetadas pelos espaçamentos, nem pelas profundidades de plantio utilizadas. Também não ocorreu interação entre os tratamentos estudados. Para ocorrerem decréscimos significativos nas percentagens médias de amido das raízes, são necessários fatores que provoquem forte impacto sobre o desenvolvimento normal das plantas. Um dos fatores é a competição com plantas daninhas (STROHHAECKER et al., 2000) (Figuras 1 e 2).

A produtividade de raízes tuberosas não manifestou variações significativas do espaçamento em fileiras duplas em relação às fileiras simples QUEIROZ et al. (1988) tiveram resultados similares. MATTOS et al.(1983); MATTOS et al. (1984); BESSA

Ciência Rural, v. 33, n. 3, mai-jun, 2003. 


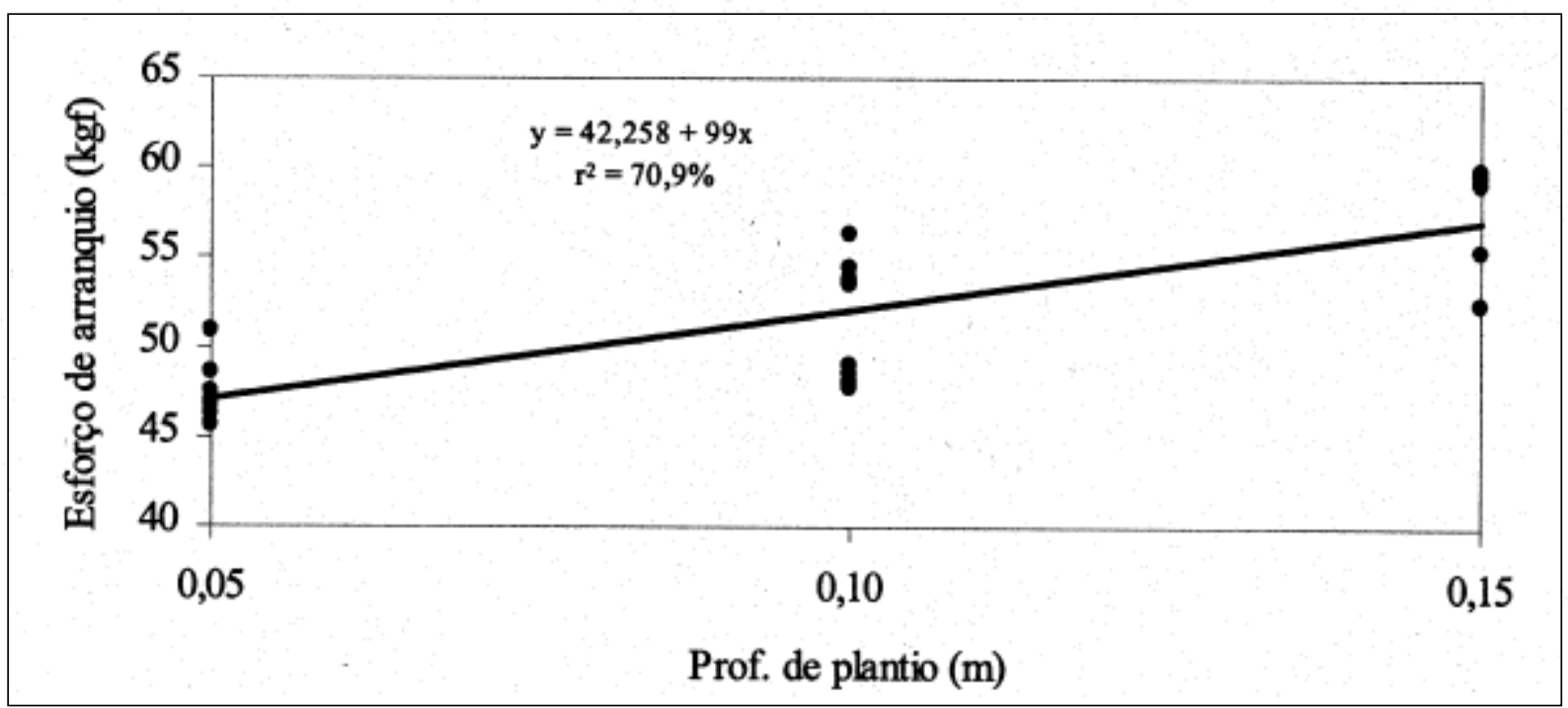

Figura 1 - Esforço de arranquio (kgf) por planta de mandioca

et al.(1986) tiveram resultados positivos do espaçamento em fileiras duplas sobre o espaçamento simples. O espaçamento de fileiras duplas pode, no entanto, possibilitar a implantação de uma cultura intercalar (entre os espaçamentos maiores), sem prejuízo à mandioca. $\mathrm{O}$ feijão e o amendoim podem ser utilizados facilmente nesse consórcio, como também recomendou MATTOS et al. (1990) e MATTOS et al. (1994).

A profundidade de plantio com $0,10 \mathrm{~m}$ proporcionou a melhor produtividade de raízes, diferindo significativamente das demais profundidades.
Este resultado concordou com os obtidos por FILGUEIRA (1980) e foi antagônico aos resultados obtidos por BRIEGUER \& GRANER (1941), que consideraram a profundidade de $0,05 \mathrm{~m}$ como a que forneceu as melhores condições de aeração e formação das raízes. Entretanto, os mesmos autores recomendaram uma profundidade um pouco maior, para melhorar as condições de umidade das manivas. NORMANHA \& PEREIRA (1950) também encontraram melhores resultados em manivas plantadas na profundidade de $0,05 \mathrm{~m}$, recomendando, porém, uma

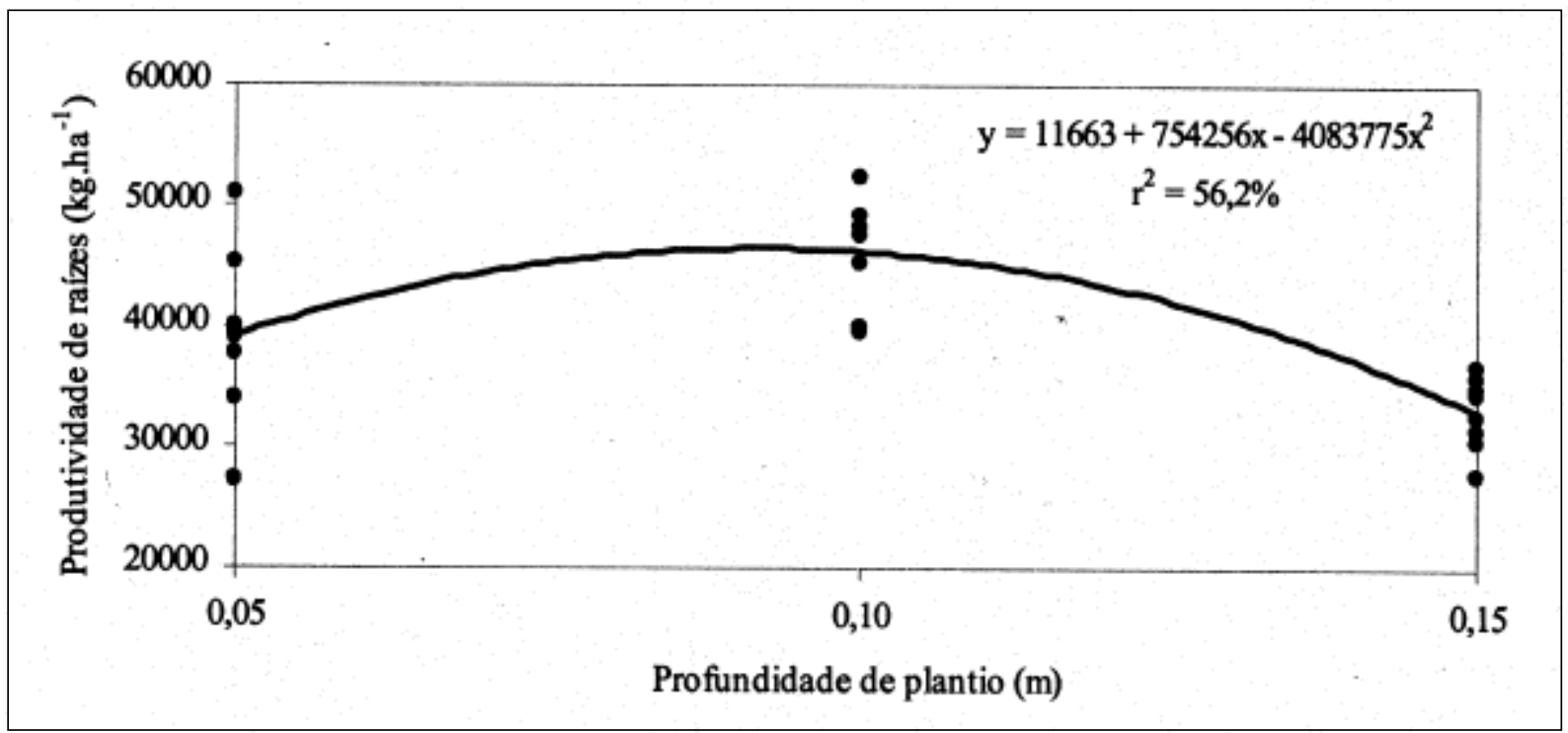

Figura 2 - Produtividade de raízes $\left(\mathrm{kg} \mathrm{ha}^{-1}\right)$

Ciência Rural, v. 33, n. 3, mai-jun, 2003. 
profundidade um pouco maior, para diminuir os riscos de perda de manivas por falta de precipitação pluvial após o plantio. Não houve interação entre os fatores em relação à produtividade de raízes tuberosas.

A produtividade de amido não foi afetada significativamente pelos espaçamentos e não houve interação entre os tratamentos estudados. Entretanto, o plantio a $0,10 \mathrm{~m}$ foi significativamente superior ao tratamento com $0,15 \mathrm{~m}$ de profundidade.

Para aumentar a produtividade de amido, além do aumento da produtividade de raízes, é importante a utilização de cultivares com teor de amido mais elevados.

Para as variáveis estudadas em que o fator profundidade apresentou-se significativo estatisticamente, os resultados indicaram que para o esforço de arranquio por planta o modelo linear foi significativo, enquanto que para o índice de tombamento, esforço específico, produção de raízes e produção de amido o modelo quadrático é que foi significativo.

\section{CONCLUSÕES}

A disposição das linhas em fileiras duplas e simples não afetou significativamente o resultado de nenhuma das variáveis estudadas. Porém, o plantio em fileiras duplas pode ser utilizado, pois facilita os tratos culturais, além de possibilitar a consorciação com outras culturas.

O plantio das manivas na profundidade de $0,15 \mathrm{~m}$ reduziu significativamente o índice de tombamento. Por outro lado, dificultou a colheita, devido à maior resistência ao arranquio manual, além de reduzir significativamente a produtividade de raízes e amido. O plantio com $0,10 \mathrm{~m}$ de profundidade proporcionou a melhor produtividade de raízes e de amido. Não houve interação entre os tratamentos (espaçamentos e profundidades de plantio) para as variáveis estudadas.

\section{REFERÊNCIAS BIBLIOGRÁFICAS}

ALMEIDA, F.S. de. Controle de plantas daninhas em plantio direto. Londrina : IAPAR, 1991. 34p.

BESSA, J.M.G.; LIMA. J.A.D. de; CESAR, F. Plantio de mandioca em fileiras duplas: uma prática viável em Pernambuco. Rev Bras Mandioca, Cruz das Almas (BA), v.5, n.1, p.103$110,1986$.

BRIEGUER, F.G.; GRANER, E.A. Polaridade e regeneração nas estacas de mandioca. Rev Agric, v.16, p.230-246, 1941.

BUENO, A. Comportamento de genótipos contrastantes de mandioca em diferentes sistemas de plantio. Pesq Agropec Bras, Brasília, v.21, n.6, p.631-640, 1986.

CALEGARI, A. Manejo de adubação verde. In ENCONTRO NACIONAL DE ROTAÇÃO DE CULTURAS, 2., 1992, Campo Mourão. Anais... Campo Mourão, 1993. p.104-116.

CAMPOS, H. dos R., SENA, Z.F. de. Profundidade do sistema radicular do aipim maragogipe (Manihot esculenta Crantz) em diferentes idades. Cruz das Almas (BA) : Escola de Agronomia, UFB, 1974. 9p.

CELIS, E.; TORO, J.C. Métodos de semeadura e cuidados iniciais a tomar na cultura da mandioca. In: Curso Especial de Aperfeiçoamento para pesquisadores de Mandioca. Cali, Colombia : 1974, p.182-186.

DERPSCH, R. Adubação verde e rotação de culturas. In: ENCONTRO NACIONAL DE PLANTIO DIRETO, 3., 1985, Ponta Grossa. Anais... Ponta Grossa : Fundação ABC, 1985. p.85-104.

FILGUEIRA, M.A. Comportamento de três cultivares de mandioca (Manihot esculenta Crantz) em relação ao comprimento do tolete e profundidade de plantio. 1980. 57f. Dissertação (Mestrado em Agronomia) - Universidade Federal de Lavras.

GABRIEL FILHO, A. et al. Preparo convencional e cultivo mínimo do solo na cultura da mandioca em condições de adubação verde com ervilhaca e aveia. Ciência Rural, Santa Maria, v.30, n.6, p.953-957, 2000.

GROSMAN, J.; FREITAS, A.C. Determinação do teor de matéria seca pelo peso específico em raízes de mandioca. Rev Agron, Porto Alegre, p.160-162, 1950.

MATTOS, P.L.P. de; SOUZA, A. da S.; CALDAS, R.C. Direcionamento do sistema radicular da mandioca em fileiras duplas. Rev Bras Mandioca, Cruz das Almas (BA), v.1, n.1, p.67-70, 1982 .

MATTOS, P.L.P. de; SOUZA, A. da S.; CALDAS, R.C. Adaptação do espaçamento em fileiras duplas para a cultura da mandioca (Manihot esculenta Crantz). Rev Bras Mandioca, Cruz das Almas (BA), v.2, n.2, p.13-22, 1983.

MATTOS, P.L.P. de; SOUZA, A. da S.; CALDAS, R.C. Sistemas de plantio de mandioca em fileira dupla no Brasil. Rev Bras Mandioca, Brasilia (DF), v.3, p.87-94, 1984.

MATTOS, P.L.P. de; SOUZA, A. da S.; CALDAS, R.C. Consorciação de mandioca plantada em fileiras duplas com feijão. Rev Bras Mandioca, Cruz das Almas (BA), v. 9, n. 1/2, p.83-90, 1990.

MATTOS, P.L.P. de; SOUZA, A. da S.; CALDAS, R.C. Cultivo da mandioca e amendoim em sistemas consorciado e monocultivo. Rev Bras Mandioca, Cruz das Almas (BA), v.13, n.1, p.29-45, 1994.

MONEGAT, C. Plantas de cobertura do solo: Características e manejo em pequenas propriedades. Chapecó : Ed. do Autor, 1991. 337p.

NORMANHA, E.S.; PEREIRA, A.S. Aspectos econômicos da cultura da mandioca (Manihot utilissima Pohl). Bragantia, v.10, n.7, p.179-202, 1950.

Ciência Rural, v. 33, n. 3, mai-jun, 2003. 
QUEIROZ, G.M. de et al. Arranjo espacial e população de plantio em mandioca consorciada com caupi. Rev Bras Mandioca, Cruz das Almas (BA), v.7, n.2, p.1-6. 1988 .

STROHHAECKER, L. et al. Esforço para o arranquio manual, rendimento de raízes e teores de amido de mandioca submetida à capina manual e mecânica no plantio direto na palha. In:
REUNIÃO BRASILEIRA DE MANEJO E CONSERVAÇÃO DO SOLO E DA ÁGUA, 13., 2000, Ilhéus. Anais... Ilhéus : SBCS, 2000. (CD-ROM).

TAN, K.H.; BERTRAND, A.R. Cultivation and fertilization of cassava. In: HENDERSHOTT, C.H., et al. A Literature Review and Research Recomendations on Cassava. Athens, Georgia : University of Georgia, 1972. p.37-72.

Ciência Rural, v. 33, n. 3, mai-jun, 2003. 